\title{
Matrix Metalloproteinase 9 Measurement
}

National Cancer Institute

\section{Source}

National Cancer Institute. Matrix Metalloproteinase 9 Measurement. NCI Thesaurus. Code C80197.

The determination of the amount of matrix metalloproteinase 9 present in a sample. 